\title{
The effect of monohydroxyethylrutoside on doxorubicin-induced cardiotoxicity in patients treated for metastatic cancer in a phase II
} study

\section{AME Bruynzeel, ${ }^{*, 1}$, HWM Niessen ${ }^{2,3,4}$, JGF Bronzwaer ${ }^{5}$, JJM van der Hoeven ${ }^{6}$, J Berkhof ${ }^{7}$, A Bast ${ }^{8}$, WJF van der Vijgh ${ }^{1,8}$ and CJ van Groeningen'}

'Department of Medical Oncology, 2 PK BR 010, VU University Medical Center, De Boelelaan III7, Amsterdam 1081 HV, The Netherlands; ${ }^{2}$ Department of Pathology, VU University Medical Center, Amsterdam 1081 HV, The Netherlands; ${ }^{3}$ ICaR-VU, VU University Medical Center, Amsterdam 1081 HV, The Netherlands; ${ }^{4}$ Department of Cardiac Surgery, VU University Medical Center, Amsterdam 1081 HV, The Netherlands; ${ }^{5}$ Department of Cardiology, VU University Medical Center, Amsterdam 1081 HV, The Netherlands; ${ }^{6}$ Department of Clinical Epidemiology and Biostatistics, VU University Medical Center, Amsterdam 1081 HV, The Netherlands; ${ }^{7}$ Department of Internal Medicine, Ziekenhuis Amstelland, Amstelveen II86 AM,

The Netherlands; ${ }^{8}$ Department of Pharmacology and Toxicology, Faculty of Medicine, University of Maastricht, Maastricht 6200 MD, The Netherlands

The purpose of this study was to investigate the cardioprotective effect of the semisynthetic flavonoid 7-monohydroxyethylrutoside (monoHER) on doxorubicin (DOX)-induced cardiotoxicity in a phase II study in patients with metastatic cancer. Eight patients with metastatic cancer were treated with DOX preceded by a 10 min i.v. infusion of $1500 \mathrm{mg} \mathrm{m}^{-2}$ monoHER. Five patients were examined by endomyocardial biopsy after reaching a cumulative dose of $300 \mathrm{mg} \mathrm{m}^{-2}$. Histopathological changes in the cardiomyocytes (Billingham score) were compared with those described in literature for patients treated with DOX only. The mean biopsy score of the patients was higher (2.7) than the mean score (I.4) of historical data of patients who received similar cumulative doses of DOX. Although there is a considerable variability in few investigated patients, it was indicative that monoHER enhanced DOX-induced cardiotoxicity. However, the antitumour activity of DOX seemed better than expected: three of the four patients with metastatic soft-tissue sarcoma had a partial remission and the fourth patient stable disease. It is likely that the relatively high dose of monoHER is responsible for the lack of cardioprotection and for the high response rate in patients with soft-tissue sarcoma possibly by depleting the glutathione defense system in both heart and tumour.

British Journal of Cancer (2007) 97, 1084-1089. doi:I0.1038/sj.bjc.6603994 www.bjcancer.com

Published online 16 October 2007

(C) 2007 Cancer Research UK

Keywords: monoHER; monohydroxyethylrutoside; doxorubicin; cardiotoxicity; clinical phase II study

The anthracycline doxorubicin (DOX) is widely used in the treatment of several malignancies in adult and paediatric patients. Treatment with DOX is limited by a dose-dependent cardiotoxicity, which may lead to late side effects resulting in severe morbidity and mortality (Steinherz et al, 2001; Lipshultz et al, 2005). Although the 5-year survival of childhood cancer has improved from 30 to $70 \%$ in the last 40 years, the risk of death from cardiac events in these survivors is eight times higher than that in the normal population (Wouters et al, 2005). Besides this, combining DOX with other anticancer drugs, for example, taxanes and trastuzumab, increases efficacy, but unfortunately also augments cardiotoxicity (Seidman et al, 2002; Minotti et al, 2004)

Although the mechanism of DOX-induced cardiotoxicity is still not fully understood, a major role has been ascribed to the induction of free radicals (Horenstein et al, 2000; Hrdina et al, 2000; Xu et al, 2001). The cardiomyocyte is particularly vulnerable

*Correspondence: Dr AME Bruynzeel; E-mail: ame.bruynzeel@vumc.nl Revised 16 August 2007; accepted 23 August 2007; published online 16 October 2007 to free radical injury because of properties such as a low antioxidant status (Doroshow et al, 1980; Iarussi et al, 2000). Presently, the cardioprotectant dexrazoxane is the only drug with proven efficacy (Cvetkovic and Scott, 2005). A recent review recommended the use of dexrazoxane if the risk of cardiotoxicity is high. However, clinicians should weigh its cardioprotective effect against the risk of a possible decrease of antitumour activity (Van Dalen et al, 2005). Preclinical experiments showed that the flavonoid 7-monohydroxyethylrutoside (monoHER) is a potential protective agent against DOX-induced cardiotoxicity without interfering with its antitumour activity (Van Acker et al, 1997, 2000). Radical scavenging and iron chelating properties are the supposed mechanisms of action of monoHER (Haenen et al, 1993; Van Acker et al, 1993). No serious side effects were observed in a clinical phase I study up to a dose of $1500 \mathrm{mg} \mathrm{m}^{-2}$. At this dose, the pharmacokinetic end points were reached, that is, $C_{\max }$ and $\mathrm{AUC}^{\infty}$ were comparable to those obtained in mice under protecting conditions. Therefore, this dose was evaluated in a phase II study (Willems et al, 2006).

In the present study, we evaluated the cardioprotective properties of $1500 \mathrm{mg} \mathrm{m}^{-2}$ monoHER given as a $10 \mathrm{~min}$ i.v. infusion 
before DOX in patients with metastatic cancer. For the early sensitive and specific detection of DOX-induced cardiotoxicity, endomyocardial biopsies were taken (Meinardi et al, 1999).

\section{MATERIALS AND METHODS}

\section{Patient selection}

Patients with metastatic solid tumours were entered when they received a DOX-based chemotherapy regimen with a dosage of $\mathrm{DOX} \geqslant 50 \mathrm{mg} \mathrm{m}^{-2}$ per cycle and an infusion duration $\leqslant 1 \mathrm{~h}$. Patients had a WHO performance status of $\leqslant 2$ and a life expectancy of $\geqslant 3$ months. They also had adequate organ functions. Their left ventricular ejection fraction (LVEF), measured by multigated radionuclide angiography, was $>50 \%$. Patients were excluded if they had received prior anthracyclines, had prior or actual cardiovascular disease or had prior radiotherapy to the mediastinum.

All patients gave written informed consent and the protocol was approved by the Medical Ethical Review Committee of the VU University Medical Center (VUMC). Patients were enrolled between September 2003 and March 2006.

\section{Treatment}

7-Monohydroxyethylrutoside was provided by Novartis Consumer Health (Nyon, Switzerland). The drug was formulated by the Department of Pharmacy, VUMC, Amsterdam as described before (Willems et al, 2006). Formulated DOX (doxorubicin hydrochloride, $2 \mathrm{mg} \mathrm{ml}^{-1}$ ) was obtained from Pharmachemie B.V. (Haarlem, the Netherlands).

7-Monohydroxyethylrutoside was administered i.v. in $10 \mathrm{~min}$ at a dose of $1500 \mathrm{mg} \mathrm{m}^{-2} 60 \mathrm{~min}$ before every DOX administration. If cardiotoxicity would be observed in the first three evaluable patients, administration according to this dosing scheme would be changed and a following patient would receive DOX infusion either immediately after monoHER (because in plasma and heart, $C_{\max }$ of monoHER is obtained immediately after the end of infusion; Abou El Hassan et al, 2003; Willems et al, 2006) or with an interval of $2 \mathrm{~h}$ (to give monoHER the opportunity to convert into an active metabolite, if any). If cardiotoxicity was maintained in both patients, then the study would be finished. If one of the two patients shows cardioprotection, then 10 additional patients will be treated with the protecting scheme.

\section{Patient evaluation}

Before starting, patients were evaluated by a full blood count, serum biochemistry including liver function tests, lactate dehydrogenase, and cholesterol. Risk factors for cardiovascular disease were also evaluated. An LVEF and an ECG were performed before entry into the study.

Every subsequent administration of monoHER and DOX was preceded by a full blood count, liver enzymes, serum creatinine and a routine 12-lead ECG. A complete blood count was also done 10 days after chemotherapy.

After a cumulative dose of $300 \mathrm{mg} \mathrm{m}^{-2} \mathrm{DOX}$, an endomyocardial biopsy was performed and the LVEF was measured. The latter was repeated at least 3 weeks after the last dose of DOX with a biopsy if possible. For logistic reasons, the biopsy of patient no. 8 was done after a cumulative dose of $375 \mathrm{mg} \mathrm{m}^{-2}$ DOX.

\section{Endomyocardial biopsy}

During a left heart catheterisation, a $104 \mathrm{~cm}$, seven french biopsy forceps was used to obtain tissue from the left ventricle. Three to four specimens $0.5-1 \mathrm{~mm}$ in diameter were obtained. The speci- mens were fixed in $4 \%$ buffered formaldehyde and prepared for electron microscopy.

\section{Histological analysis and biopsy scores}

After fixation in $4 \%$ buffered formaldehyde, the heart tissue was post fixed in $1 \%$ osmium tetroxide. The tissue was then dehydrated through a graded series of ethanol solutions of $70-95 \%$ and embedded in JB-4 Plus resin. Thereafter, $0.5-3.0 \mu$ m thick sections were cut with a glass knife. These semithin sections were processed for electron microscopy. Cardiomyocytes with $>2$ microvacuoles, macrovacuoles and/or loss of myofibrils were counted as deviant. The morphological grade determined from the specimens examined by electron microscopy was scored on a six-point scale previously described by Billingham et al (1978) (Bristow et al, 1982): in grade 0 , cells are normal; in grade 1, 1.5, 2 and 2.5 deviant cells are $<5,5-15,16-25$ and $26-35 \%$, respectively; in grade 3 , cell damage is $>35 \%$.

\section{Off-study criteria}

Patients went off study in case of progressive disease, a serious cardiac event or other events that precluded further treatment. Criteria described by Shapiro et al (1999) were used for diagnosis of cardiac events. Episodes of cardiac dysfunction were characterised according to the NYHA functional classification (Seidman et al, 2002).

\section{Assessment of tumour response}

Assessment of tumour response was carried out every 2-3 cycles by CT scan, using standard ECOG criteria (Oken et al, 1982).

\section{Statistical analysis}

This trial was an open-labelled, controlled study. We compared the data of our patients with those of 14 patients from the study of Torti et al (1986) treated with a cumulative dose of DOX between 200 and $300 \mathrm{mg} \mathrm{m}^{-2}$ alone using the $\chi^{2}$ test. Our hypothesis was that adding monoHER to DOX would eliminate its cardiotoxicity up to a cumulative dose of at least $300 \mathrm{mg} \mathrm{m}^{-2}$, which was the upper limit of the dose interval of DOX from Torti's patients. To achieve a power of $80 \%, 11$ patients would be required. This sample size was obtained when applying the $\chi^{2}$ test with significance level 0.05 and assuming a response rate (i.e. no cardiac damage) in the experimental arm of $80 \%$. If at least five patients show DOX-induced damage, statistical significance cannot be achieved anymore and the study should be stopped.

\section{RESULTS}

Eight patients meeting the inclusion criteria were enrolled (Table 1).

Analysis of risk factors indicated that patient no. 6 was treated for hyperhomocysteinaemia. Two other patients had an elevated body mass index of 29.1 (no. 1) and 30.1 (no. 7), indicating overweight and obesity, respectively. Patient no. 2 had hyperlipidaemia (LDL of $6.3 \mathrm{mmoll}^{-1}$; normal values $\leqslant 5.0$ ). None of the other patients had risk factors for cardiovascular disease. All patients were classified as NYHA class ${ }^{2}$ and had a performance status $(\mathrm{WHO}) \leqslant 2$.

Five patients received a cumulative dose of $\geqslant 300 \mathrm{mg} \mathrm{m}^{-2}$ DOX and underwent a biopsy. In the other three patients, DOX was discontinued before this dose, due to progressive disease.

Patient no. 3 received irradiation after he was operated for a parapharyngeal tumour with a modified radical neck dissection at his right site because of a malignant peripheral nerve sheet tumour. Both patient nos. 7 and 8 received postoperative 
Table I Patient characteristics

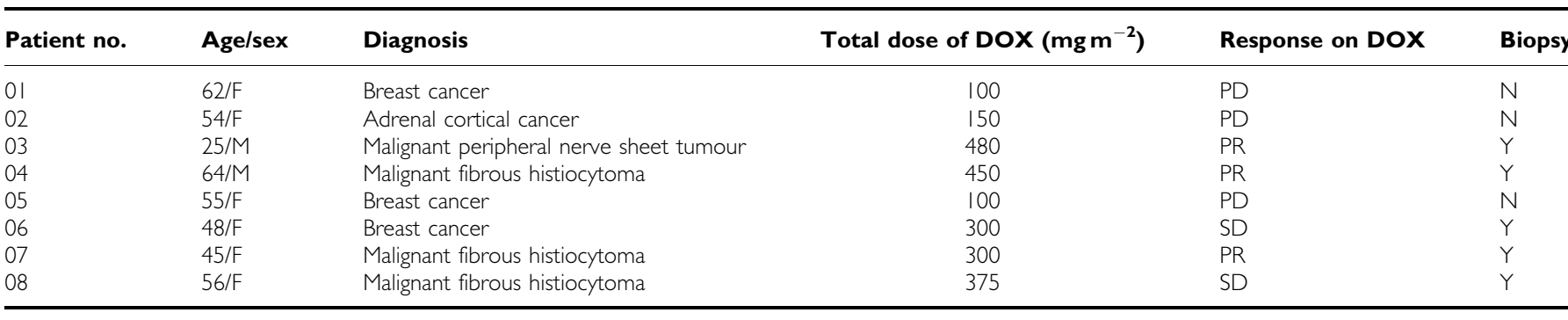

Age in years; sex $\mathrm{F}$ female, $\mathrm{M}$ male; assessment of tumour response was done by using standard $\mathrm{ECOG}$ criteria $(\mathrm{PD}=$ progressive disease; $\mathrm{PR}=$ partial remission; $\mathrm{SD}=$ stable disease); $Y=$ yes; $N=$ no.

irradiation after resection of the malignant fibrous histiocytoma in their right upper leg.

\section{Treatment with DOX preceded by monoHER}

During monoHER infusion, two patients reported adverse events. One patient described a sensation of fullness in his stomach, which developed during infusion of monoHER and disappeared soon after the end of the infusion. The other patient experienced itching in the skin of the neck during monoHER infusion and disappearing rapidly after the infusion. Both patients experienced the events during each cycle. A causal relationship cannot be excluded. The other six patients did not experience adverse events.

None of the patients had a delay in receiving subsequent cycles of chemotherapy. As expected, all patients developed chemotherapy-related leukopaenia, which recovered before the start of the next cycle. No disturbances of liver enzymes and serum creatinine were noted.

\section{Biopsy scores}

The endomyocardial biopsy scores are shown in Table 2. After $300 \mathrm{mg} \mathrm{m}^{-2}$, the first three evaluable patients showed abnormalities consistent with DOX-induced cardiotoxicity, that is the presence of microvacuoles dominated (Figure 1). In patient nos. 3 and 4, microvacuoles were present in 52 and $20 \%$ of the cardiomyocytes, respectively. In patient no. $6,33 \%$ of the cardiomyocytes had $>2$ small vacuoles per cardiomyocyte. Because each of the first three evaluable patients showed cardiotoxicity, it was decided to stop this dosing scheme. The time interval between monoHER and DOX administration was changed and patient no. 7 received DOX immediately after monoHER. In the biopsy of this patient, microvacuolisation was observed in $60 \%$ of the cardiomyocytes. After this result, the interval was changed again and patient no. 8 received DOX $2 \mathrm{~h}$ after monoHER administration. In this patient, microvacuolisation was detected in $49 \%$ of the cardiomyocytes. After these results, the study had to be considered negative, because no cardioprotective effect of monoHER was observed in the five patients.

Second biopsies were also taken after $450-480 \mathrm{mg} \mathrm{m}^{-2}$ of DOX in two patients (Table 3). The score of patient no. 4 had increased from 2.0 to 2.5, whereas the score of patient no. 3 remained 3 . Striking was the increase in loss of myofibrils in addition to the microvacuoles observed in the cardiomyocytes after $300 \mathrm{mg} \mathrm{m}^{-2}$ (Figure 2).

Ten months after his last cycle of DOX, patient no. 4 underwent a third biopsy. This time, the cardiomyocytes showed recuperation of myofibrils, whereas the number of abnormal cardiac cells (microvacuolisation) was less than that in the first two biopsies (score 2).

No complications occurred during the seven biopsy procedures in the first four patients. However, the last patient (no. 8)
Table 2 Patients who received at least a cumulative dose (cum. dose) of $300 \mathrm{mg} \mathrm{m}^{2}$ DOX and underwent an endomyocardial biopsy

\begin{tabular}{llcc}
\hline $\begin{array}{c}\text { Biopsy score cum. dose (no. of } \\
\text { Patientcycles } \times \text { dose per cycle, time of bolus } \\
\text { infusion/ } \mathbf{\Delta t} \text { t/grade }\end{array}$ & $\begin{array}{c}\text { LVEF } \\
\text { before } \\
\text { no. }\end{array}$ & $\begin{array}{c}\text { LVEF after } \\
\text { Lox }\end{array}$ & $\mathbf{3 0 0} \mathbf{~ m g ~ m}^{-2}$ \\
\hline 03 & $300\left(4 \times 75,15^{\prime}\right) / 60 /$ grade 3 & $71 \%$ & $67 \%$ \\
04 & $300\left(4 \times 75,15^{\prime}\right) / 60 /$ grade 2 & $72 \%$ & $60 \%$ \\
06 & $300\left(6 \times 50,15^{\prime}\right) / 60 /$ grade 2.5 & $52 \%$ & $\mathrm{ND}$ \\
07 & $300\left(4 \times 75,15^{\prime}\right) / / 10 /$ grade 3 & $75 \%$ & $63 \%$ \\
08 & $375\left(5 \times 75,15^{\prime}\right) / / 20 /$ grade 3 & $65 \%$ & $63 \%$ \\
\hline
\end{tabular}

$\Delta t=$ time between end of monoHER infusion and start of DOX infusion in minutes. The morphological grade was scored on a six-point scale previously described by Billingham and Bristow; $L V E F=$ left ventricular ejection fraction.

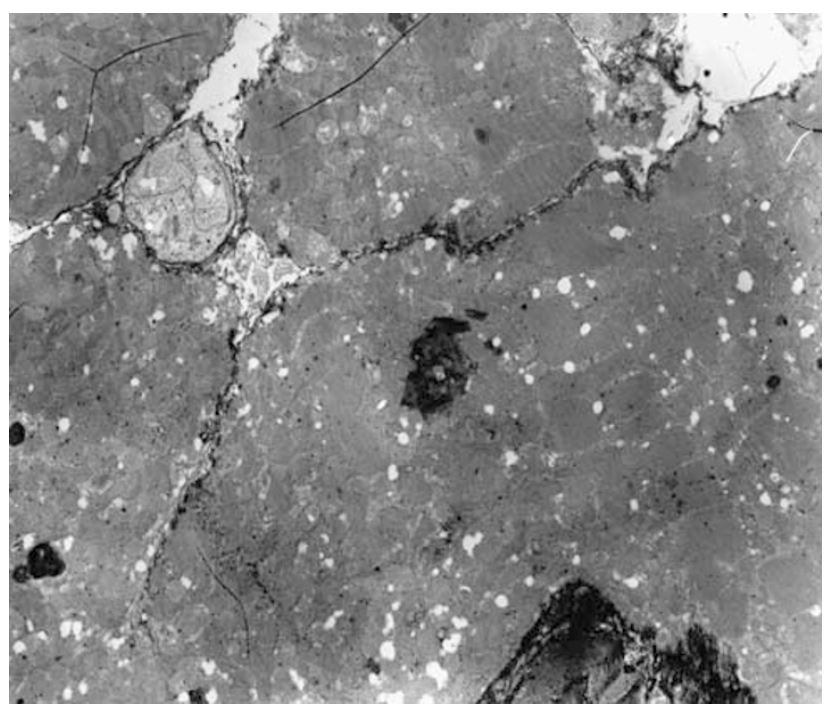

Figure I Heart tissue from patient no. 3 after $300 \mathrm{mgm}^{-2}$ DOX Evaluation by electron microscopy demonstrated an abundant presence of microvacuoles in the cardiomyocytes.

developed a small pericardial effusion after the biopsy. This was preceded by chest pain and transient supraventricular rhythm disturbances. These sequelae disappeared within a few days and after a week she recovered and received the sixth cycle of DOX.

\section{Monitoring and evaluation of cardiac function}

In all patients, the ECG remained unchanged during therapy and no cardiac dysfunction occurred. 
Table 3 Two patients who underwent an extra endomyocardial biopsy at $>300 \mathrm{mg} \mathrm{m}^{-2}$ of DOX

\begin{tabular}{lcc}
\hline $\begin{array}{l}\text { Patient } \\
\text { no. }\end{array}$ & $\begin{array}{c}\text { Cum.dose/biopsy } \\
\text { score/LVEF }\end{array}$ & $\begin{array}{c}\text { Biopsy score/LVEF IO months after } \\
\text { the last cycle }\end{array}$ \\
\hline 03 & $480 /$ grade $3 / 53 \%$ & $\mathrm{ND} / 51 \%$ \\
04 & $450 /$ grade $2.5 / 66 \%$ & Grade $2 / 62 \%$ \\
\hline
\end{tabular}

The morphological grade was scored on a six-point scale previously described by Billingham and Bristow; $L V E F=$ left ventricular ejection fraction; ND = not done.

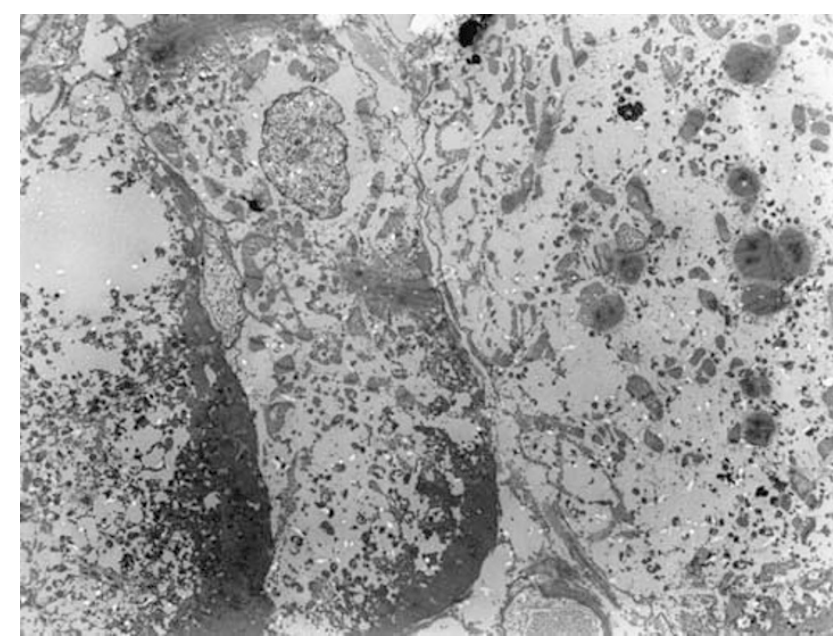

Figure 2 Heart tissue from patient no. 3 after $480 \mathrm{mg} \mathrm{m}^{-2}$ DOX. In addition to the vacuolisation, a loss of myofibrils is observed with electron microscopy.

The five patients who received at least $300 \mathrm{mg} \mathrm{m}^{-2}$ DOX started with an LVEF $>50 \%$ (Table 2). After $300-375 \mathrm{mg} \mathrm{m}^{-2}$ DOX, the LVEF decreased in 4 out of 5 patients. This decrease was not related with the biopsy score or the time interval between monoHER and DOX infusions. Unfortunately, no information on the LVEF was available for patient no. 6 .

After $480 \mathrm{mg} \mathrm{m}^{-2}$ DOX, the LVEF in patient no. 3 decreased to $53 \%$, which is a decline of $25 \%$ compared to the LVEF before starting the study $(71 \%)$. The patient had no symptoms of cardiac failure. Ten months after his last cycle of chemotherapy, the LVEF remained stable and he remained without cardiac symptoms.

The LVEF of patient no. 4 showed an initial drop from $72 \%$ before starting chemotherapy to $60 \%$ after $300 \mathrm{mg} \mathrm{m}^{-2}$ DOX (decline of $>15 \%$ ). This value remained stable up to $450 \mathrm{mg} \mathrm{m}^{-2}$ of DOX, and at 10-month follow-up the patient still had an excellent physical condition.

\section{Evaluation of tumour response}

Response to the chemotherapy was remarkable in the four patients with metastatic soft-tissue sarcoma (STS). Three of them developed a partial remission (PR), as observed on the CT scan (Table 1). In two of these patients (nos. 4 and 7), PR was maintained up to the present, that is, 30 and 16 months after the start of chemotherapy, respectively. The other patient (no. 3) had progressive disease after a PR of 9 months duration. The fourth patient (no. 8) achieved stable disease for at least 7 months, while continuing therapy with DOX up to a cumulative dose of $495 \mathrm{mg} \mathrm{m}^{-2}$.

\section{DISCUSSION}

On the basis of the promising results with monoHER observed in preclinical experiments, we performed the present phase II study in patients with metastatic cancer. The cardioprotective effect of monoHER on DOX-induced cardiotoxicity was evaluated by endomyocardial biopsy. However, the results indicated that the preclinical observations were not translated into protection against DOX-induced heart damage in humans.

The golden standard for early detection of DOX-induced cardiotoxicity is the endomyocardial biopsy, because of its high sensitivity and high specificity (Torti et al, 1986). Currently, the most common method used to detect DOX-induced cardiac damage is the evaluation of the LVEF, but usually at later stages (Kilickap et al, 2005; Villani et al, 2006). For detection of cardiotoxicity at an earlier stage, the use of biochemical markers such as atrial and brain natriuretic peptides, endothelin-1 and also cardiac troponin-T and -I have been investigated (Yamashita et al, 1995; Suzuki et al, 1998; Kilickap et al, 2005). However, large-scale studies addressing whether these biomarkers following DOX treatment will be predictive for the development of late-onset heart failure are lacking. Therefore, despite its invasiveness, we chose the endomyocardial biopsy for this evaluation.

Data of Billingham et al (1978) showed that anthracyclineinduced myocardial damage occurred in nearly all patients treated with cumulative DOX doses of $240 \mathrm{mg} \mathrm{m}^{-2}$. Therefore, we could expect detectable heart damage after a cumulative dose of $300 \mathrm{mg} \mathrm{m}^{-2}$, which would allow the registration of protection by monoHER. However, all five patients undergoing the biopsy procedure after a median cumulative dose of $300 \mathrm{mg} \mathrm{m}^{-2}$ showed DOX-induced cardiotoxicity with a mean biopsy score of 2.7 according to Billingham et al (1978). This score was independent of the time interval between monoHER and DOX infusion and much higher than the biopsy score of 1.4, which is expected after a cumulative dose of $300 \mathrm{mg} \mathrm{m}^{-2}$ DOX according to the linear regression analysis of Torti et al (1986). In our patients, mainly one of the three morphological changes, that is, small vacuoles of varying size, was observed after $300 \mathrm{mg} \mathrm{m}^{-2}$ DOX, whereas in Torti et al's study also partial or total myofibrillar loss was observed. However, in Torti's study, it is not clear after which dose this occurred. In addition to microvacuolisation, loss of myofibrils was demonstrated in two patients after higher cumulative doses of DOX. This suggests that the occurrence of microvacuoles as such is a marker of cytotoxicity of DOX treatment. Billingham et al (1977) described that these microvacuoles appear early as a swelling of the sarcoplasmic reticulum, which eventually coalesce to form large spaces in the cytoplasm (macrovacuoles). The possible change from microvacuoles into macrovacuoles in time is not clear from literature.

Thus, instead of protection, our patients had higher biopsy scores than the historical controls. However, it should be noted that the data of Torti et al (1986) were obtained after a cumulative dose of $200-300 \mathrm{mg} \mathrm{m}^{-2}$ with biopsies from the right ventricle, whereas biopsies from our patients were obtained after a cumulative dose of $300 \mathrm{mg} \mathrm{m}^{-2}$ from the left ventricle. Previously, it was shown that ultrastructural abnormalities of cardiomyocytes were more pronounced in biopsy specimens from the left ventricle than those from the right ventricle (Mortensen et al, 1986). In addition to this, there is a considerable variability in patient sensitivity to the cardiotoxic effects of DOX (Ferrans 1978; Mason et al, 1978). These data may explain a possible overestimation of the toxic effect of DOX on the heart tissue in our patients. Although heart failure is directly related to the degree of myocyte damage (Bristow et al, 1978), none of our patients developed heart failure, although the LVEF dropped by $16 \%$ in two patients, whereas it decreased in two other patients by only $4-6 \%$ (in comparison to the initial LVEF). 
In the third biopsy procedure of patient no. 4, the score of the cardiac tissue had improved. A recuperation of myofibrils in the cardiomyocytes was observed and the microvacuolisation was less. These findings are in agreement with a previous study reporting that some improvement of the histological damage may occur (Mackay et al, 1994). This is in contrast with other results, which indicated that DOX-induced cardiotoxicity is an ongoing progressive process (Billingham et al, 1978).

The contrasting effects of monoHER found in animal and human studies may be attributed to differences in metabolism between the species. Therefore, patient no. 8 was treated with a $2 \mathrm{~h}$ interval. However, this interval change did not reduce DOXinduced cardiotoxicity. In addition, no metabolites of monoHER have been detected until now. On the other hand, it cannot be excluded that during scavenging of the reactive oxygen species, the antioxidant monoHER is converted into a reactive oxidation product, which, like the oxidation product of quercetin, may be prone to form adducts with thiol groups from glutathione and proteins (Boots et al, 2005a). Depletion of glutathione may in addition to the low antioxidant status of the cardiomyocyte (Nowak and Drzwoski, 1996) reduce cardioprotection, while monoHER-protein adducts may cause additional toxicity (Boots et al, 2005b).

Another unexpected observation in our study was that three of the four patients with STS had objective remissions, while the fourth patient had stable disease. Normally, objective responses on DOX in STS patients without prior chemotherapy are approximately $25 \%$ (Santoro et al, 1995). Although our observation was done in a very limited number of patients, our result is much better than expected, because the chance of observing an objective response in four consecutive STS patients treated with DOX is $0.4 \%$. Thus, it is suggestive that monoHER enhances the antitumour activity of DOX in STS.

\section{REFERENCES}

Abou El Hassan MAI, Kedde MA, Zwiers UTH, Torun E, Haenen GRMM, Bast A, Van der Vijgh WJF (2003) Bioavailability and pharmacokinetics of the cardioprotecting flavonoid 7-monohydroxyethylrutoside in mice. Cancer Chemother Pharmacol 52: $371-376$

Billingham ME, Bristow MR, Glatstein E, Mason JW, Masek MA, Daniels JR (1977) Adriamycin cardiotoxicity: endomyocardial biopsy evidence of enhancement by irradiation. Am J Surg Pathol 1: 17-23

Billingham ME, Mason JW, Bristow MR, Daniels JR (1978) Anthracycline cardiomyopathy monitored by morphologic changes. Cancer Treat Rep 62: $865-872$

Boots AW, Balk JM, Bast A, Haenen GR (2005a) The reversibility of glutathionyl-quercetin adducts spreads oxidized quercetin-induced toxicity. Biochem Biophys Res Commun 338: 923 - 929

Boots AW, Bast A, Haenen GRMM (2005b) No role of DT-diaphorase (NQO1) in the protection against oxidized quercetin. FEBS Lett 579: $677-682$

Bristow MR, Billingham ME, Mason JW, Daniels JR (1978) Clinical spectrum of anthracycline antibiotic cardiotoxicity. Cancer Treat Rep 62: $873-879$

Bristow MR, Lopez MB, Mason JW, Billingham ME, Winchester MA (1982) Efficacy and cost of cardiac monitoring in patients receiving doxorubicin. Cancer 50: 32-41

Cvetkovic RS, Scott Jr L (2005) Dexrazoxane: a review of its use for cardioprotection during anthracycline chemotherapy. Drugs 65: 1005-1024

Debes A, Oerding M, Willers R, Gobel U, Wessalowski R (2003) Sensitization of human Ewing's tumor cells to chemotherapy and heat treatment by the bioflavonoid quercetin. Anticancer Res 23: 3359-3366

Doroshow JH, Locker GY, Meyers CE (1980) Enzymatic defenses of the mouse heart against reactive oxygen metabolites. J Clin Invest 65: $128-135$

Elangovan V, Sekar N, Govindasamy S (1994) Chemopreventive potential of dietary bioflavonoids against 20-methylcholanthrene-induced tumorigenesis. Cancer Lett 87: $107-113$
This observation is in agreement with potentiating antitumour effects of a few flavonoids observed in vitro (Elangovan et al, 1994; Sliutz et al, 1996; Debes et al, 2003). The background for this effect may be that the concentration of GSH may play a role in STS chemoresistance (Hochwald et al, 1997) and that GSH depletion may increase the antitumour efficacy (Siemann and Beyers, 1997). Thus, the same mechanism may play a role as hypothesised for the cardiomyocytes.

As a consequence of the above-mentioned aspects, there may be a dose-depending transition in the effect of monoHER, that is a high dose $\left(\geqslant 1500 \mathrm{mg} \mathrm{m}^{-2}\right)$ for obtaining a potentiating effect of the antitumour effect for at least STS and a low dose (somewhere below $1500 \mathrm{mg} \mathrm{m}^{-2}$ ) for obtaining cardioprotection. These aspects have to be elucidated further in the near future. It may be concluded that monoHER at a dose of $1500 \mathrm{mg} \mathrm{m}^{-2}$ did not protect against DOX-induced cardiotoxicity in patients with metastatic disease, but may have an enhancing effect on the antitumour activity of DOX in patients with metastatic STS. Further preclinical and clinical investigations seem to be warranted to investigate the postulated dose-depending transitional effect of monoHER.

\section{ACKNOWLEDGEMENTS}

We thank Marike Rebel, Ellen Geerligs, Emine Torun and Jan Fritz for their excellent assistance. We are thankful for the skilful cooperation with the staff of the Department of Hospital Pharmacy, the Department of Medical Oncology, the Department of Cardiology and Department of Pathology, The VU University Medical Center, Amsterdam, The Netherlands. Finally, we are very grateful to the patients who participated in this study. This work was supported in part by Grant VU-97-1525 from the Koningin Wilhelmina Foundation, Amsterdam, The Netherlands.
Ferrans VJ (1978) Overview of cardiac pathology in relation to anthracycline cardiotoxicity. Cancer Treat Rep 62: 955-961

Haenen GRMM, Jansen FP, Bast A (1993) The antioxidant properties of five $O$-(beta-hydroxyethyl) rutosides of the flavonoid mixture Venoruton. Phlebology Suppl 1: 10-17

Hochwald SN, Rose DM, Brennan MF, Burt ME (1997) Elevation of glutathione and related enzyme activities in high-grade and metastatic extremity soft tissue sarcoma. Ann Surg Oncol 4: 303-309

Horenstein MS, Van der Heide RS, L'Ecuyer TJ (2000) Molecular basis of anthracycline-induced cardiotoxicity and its prevention. Mol Gen Metab 71: $436-444$

Hrdina R, Gersl V, Klimtova I, Simunek T, Machackova J, Cerman J, Suba P (2000) Anthracycline-induced cardiotoxicity. Acta Medica 43: $75-82$

Iarussi D, Indolfi P, Galderisi M, Bossone E (2000) Cardiac toxicity after anthracycline chemotherapy in childhood. Herz 25: 676-688

Kilickap S, Barista I, Akgul E, Aytemir E, Aksoyek S, Aksoy S, Celik I, Kes S, Tekuzman G (2005) cTnT can be a useful marker for early detection of anthracycline cardiotoxicity. Ann Oncol 16: 798-804

Lipshultz SE, Lipsitz SR, Sallan SE, Dalton VM, Mone SM, Gelber RD, Colan SD (2005) Chronic progressive cardiac dysfunction years after doxorubicin therapy for childhood acute lymphoblastic leukemia. J Clin Oncol 23: $2629-2636$

Mackay B, Ewer MS, Carrasco CH, Benjamin RS (1994) Assessment of anthracycline cardiomyopathy by endomyocardial biopsy. Ultrastruct Pathol 18: $203-211$

Mason JW, Bristow MR, Billingham ME, Daniels JR (1978) Invasive and noninvasive methods of assessing adriamycin cardiotoxic effects in man: superiority of histopathologic assessment using endomyocardial biopsy. Cancer Treat Rep 62: 857-864

Meinardi M, Van der Graaf W, Van Veldhuisen DJ, Gietema JA, de Vries EG, Sleijfer DT (1999) Detection of anthracycline-induced cardiotoxicity. Cancer Treat Rev 25: 237-247 
Minotti G, Menna P, Salvatorelli E, Cairo G, Gianni L (2004) Anthracyclines: molecular advances and pharmacologic developments in antitumor activity and cardiotoxicity. Pharmacol Rev 56: 185-229

Mortensen SA, Olsen HS, Baandrup U (1986) Chronic anthracycline cardiotoxicity: haemodynamic and histopathological manifestations suggesting a restrictive endomyocardial disease. $\mathrm{Br}$ Heart $\mathrm{J}$ 55: $274-282$

Nowak D, Drzwoski J (1996) Anthracycline-induced oxidative stress - its role in the development of cardiac damage. Cancer J 9: 296-303

Oken MM, Creech RH, Tormey DC, Horton J, Davis TE, McFadden ET, Carbone PP (1982) Toxicity and response criteria of the Eastern Cooperative Oncology Group. Am J Clin Oncol 5: 649-655

Santoro A, Tursz T, Mouridsen H, Verweij J, Steward W, Somers R, Buesa J, Casali P, Spooner D, Rankin E (1995) Doxorubicin versus CYVADIC versus doxorubicin plus ifosfamide in first-line treatment of advanced soft tissue sarcomas: a randomized study of the European organization for research and treatment of cancer soft tissue and bone sarcoma group. J Clin Oncol 13: 1537-1545

Seidman A, Hudis C, Pierri MK, Shak S, Paton V, Ashby M, Murphy M, Steward SJ, Keefe D (2002) Cardiac dysfunction in the trastuzumab clinical trials experience. J Clin Oncol 20: 1215-1221

Siemann DW, Beyers KL (1997) In vivo therapeutic potential of combination thiol depletion and alkylating chemotherapy. $\mathrm{Br} J$ Cancer 68: $1071-1079$

Shapiro C, Ervin T, Welles L, Azarnia N, Keating J, Hayes DF (1999) Phase II trial of high-dose liposome-encapsulated doxorubicin with granulocyte colony-stimulating factor in metastatic breast cancer. J Clin Oncol 17: 1435 - 1441

Sliutz G, Karlseder J, Tempfer C, Orel L, Holzer G, Simon MM (1996) Drug resistance against gemcitabine and topotecan mediated by constitutive hsp70 overexpression in vitro: implication of quercetin as sensitiser in chemotherapy. Br J Cancer 74: $172-177$

Steinherz LJ, Steinherz PG, Tan CTC, Heller G, Murphy L (2001) Cardiac toxicity 4 to 20 years after completing anthracyclin therapy. JAMA 266: $1672-1677$
Suzuki T, Hayashi D, Yamazaki T, Mizuno T, Kanda Y, Komoro I, Kurabayashi M, Yamaoki K, Mitani K, Hirai H, Nagai R, Yazaki Y (1998) Elevated B-type natriuretic peptide levels after anthracycline administration. Am Heart J 136: 362-363

Torti FM, Bristow MM, Lum BL, Carter SK, Howes AE, Aston DA, Brown Jr BW, Hannigan Jr JF, Meyers FJ, Mitchell EP (1986) Cardiotoxicity of epirubicin and doxorubicin: assessment by endomyocardial biopsy. Cancer Res 46: 3722 - 3727

Van Acker FA, van Acker SA, Kramer K, Haenen GRMM, Bast A, van der Vijgh WJF (2000) 7-monohydroxyethylrutoside protects against chronic doxorubicin-induced cardiotoxicity when administered only once per week. Clin Cancer Res 6: 1337-1341

Van Acker SA, Boven E, Kuiper K, van den Berg DJ, Grimbergen JA, Kramer K, Bast A, van der Vijgh WJ (1997) Monohydroxyethylrutoside, a dose-dependent cardioprotective agent, does not affect the antitumor activity of doxorubicin. Clin Cancer Res 3: 1747-1754

Van Acker SA, Towart R, Husken BCP, de Jong J, van der Vijgh WJ, Bast A (1993) The protective effect of Venoruton and its constituents on acute doxorubicin-induced cardiotoxicity. Phlebology 1: $31-32$

Van Dalen EC, Caron HN, Dickinson HO, Kremer LC (2005) Cardioprotective interventions for cancer patients receiving anthracyclines. The Cochrane Database of Systematic Reviews, Issue 1: 2005

Villani F, Meazza R, Materazzo C (2006) Non-invasive monitoring of cardiac hemodynamic parameters in doxorubicin-treated patients: comparison with echocardiography. Anticancer Res 26: 797-801

Willems AM, Bruynzeel AME, Kedde MA, van Groeningen CJ, Bast A, van der Vijgh WJ (2006) A phase I study of monohydroxyethylrutoside in healthy volunteers. Cancer Chemother Pharmacol 57: 678-684

Wouters KA, Kremer LC, Miller TL, Herman EH, Lipshultz SE (2005) Protecting against anthracycline-induced myocardial damage: a review of the most promising strategies. Br J Haematol 131: $561-578$

Xu MF, Tang PL, Qian ZM, Ashraf M (2001) Effects by doxorubicin on the myocardium are mediated by oxygen free radicals. Life Sci 68: 889-901

Yamashita J, Ogawa M, Shirakusa T (1995) Plasma endothelin-1 as a marker for doxorubicin cardiotoxicity. Int J Cancer 62: 542-547 